\title{
Pemanfaatan Pekarangan sebagai Upaya Peningkatan Ketahanan Pangan
}

\author{
Aliefman Hakim ${ }^{*}$, Ellend Putri Kurnia ${ }^{2}$, Nurul Lasmini ${ }^{2}$, Ade Nusa Putra Dinata ${ }^{3}$, Idmayanti ${ }^{4}$,

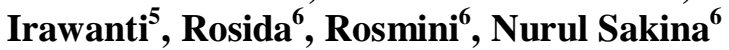 \\ ${ }^{1}$ Study Program of Chemistry Education, University of Mataram, Mataram, Indonesia; \\ ${ }^{2}$ Study Program of Forestry, University of Mataram, Mataram, Indonesia; \\ ${ }^{3}$ Study Program of Electrical Engineering, University of Mataram, Mataram, Indonesia; \\ ${ }^{4}$ Study Program of Chemistry, University of Mataram, Mataram, Indonesia; \\ ${ }^{5}$ Study Program of Food Science and Technology, University of Mataram, Mataram, Indonesia; \\ ${ }^{6}$ Study Program of Animal Science, University of Mataram, Mataram, Indonesia;
}

DOI: $\underline{\text { https://doi.org/10.29303/jpmsi.v3i1.107 }}$

Citation: Hakim, A., Kurnia, E. P., Lasmini, N., Dinata, A. N. P., Idmayanti, I., Irawanti, I., Rosida, R. Rosmini, R., Sakina, N. 2021. Pemanfaatan Pekarangan sebagai Upaya Peningkatan Ketahanan Pangan. Jurnal Pengabdian Masyarakat Sains Indonesia (JPMSI). 3(1):226-234.

Article history

Received: April $18^{\text {th }} 2021$

Revised: May $30^{\text {th }} 2021$

Accepted: June $25^{\text {th }} 2021$

*Corresponding Author: Aliefman Hakim, Study Program of Chemistry Education, University of Mataram, Mataram, Indonesia Email:

alefmanhakim27@gmail.com

\begin{abstract}
Telaga Baru A is one of the area located in Telaga Bertong Village, Taliwang District, West Sumbawa Regency, West Nusa Tenggara Province, which had not used the house yard to improve the community's economy and national food security. One of the applicable steps that can be applied to optimize the yards of residents is the "Sustainable Food Homes" program. The Sustainable Food House program was a program of community service and empowerment in the local village in optimizing the house yard by planting organic vegetable seeds using the verticulture method. The verticulture method was a technique of cultivating plants vertically, so that planting was carried out in stages. The stages of the verticulture method were preparation of tools and materials, seeding, filling the soil in polybags, transferring seeds, and monitoring which was carried out in the morning and during the day. The vegetable seeds used include cabbage seeds, mustard greens, chilies, lettuce, celery, purple eggplant, fresh eggplant, water spinach, onions and spinach. To support plant growth and productivity, composting and application of compost to plant seeds was also carried out in this service activity. The result of implementing the Sustainable Food House and making compost was the improvement of the skills of the local people, so they were able to continue the program with village officials and achieve the goals they want to achieve.
\end{abstract}

Keywords: Vegetable Seeds, Home Yard, Compost, Verticulture

\section{Pendahuluan}

Kecamatan Taliwang merupakan salah satu kecamatan yang ada di Kabupaten Sumbawa Barat. Taliwang merupakan ibu kota Kabupaten Sumbawa Barat, Nusa Tenggara Barat, Indonesia, dengan luas wilayah 37. $593 \mathrm{Ha}$ dengan persentase $20,33 \%$. Jumlah penduduk Kecamatan Taliwang yaitu sebanyak 52.617 jiwa dengan pembagian jumlah perempuan yaitu 26.199 jiwa dan jumlah laki-laki yaitu 26. 498 jiwa. Ada 7 kelurahan yang terdapat di taliwang yaitu Arab Kenangan, Bugis, Dalam, Kuang, Menala, Sampir, Telaga Bertong (Wikipedia, 2020).

Telaga Bertong adalah salah satu desa atau kelurahan yang terletak di Kecamatan Taliwang, Kabupaten Sumbawa Barat, Memiliki kodepos 84455. Target kawasan rumah pangan lestari yaitu terletak di lingkungan Telaga Baru A RT. 04/RW. 01, Kelurahan Telaga Bertong, Kecamatan 
Hakim et al, Jurnal Pengabdian Masyarakat Sains Indonesia 2021, 3 (1): 226-234. DOI: https://doi.org/10.29303/jpmsi.v3i1.107

Taliwang, Kabupaten Sumbawa Barat. Kelurahan Telaga Bertong terbagi atau 4 lingkungan yaitu lingkungan Telaga Baru A, Lingkungan Bertong A, Lingkungan Bertong $\mathrm{B}$ dan Lingkungan Perjuk Balat. Luas Wilayah Kelurahan Telaga Bertong secara keseluruhan yaitu $21,44 \mathrm{~km}^{2}$, sedangkan menurut penggunaannya luas wilayah pemukiman $319,73 \mathrm{ha} / \mathrm{m}^{2}$, persawahan $994,14 \mathrm{ha} / \mathrm{m}^{2}$, perkebunan $326,07 \mathrm{ha} / \mathrm{m}^{2}$, kuburan $02,73 \mathrm{ha} / \mathrm{m}^{2}$, perkantoran $05,50 \mathrm{ha} / \mathrm{m}^{2}$, dan prasarana umum lainnya $06,75 \mathrm{ha} / \mathrm{m}^{2}$. Batas-batas wilayah sebagai berikut: sebelah utara berbatasan dengan Desa Banjar dan Kelurahan Bugis, sebelah timur berbatasan dengan kelurahan kuang, sebelah selatan berbatasan dengan desa labuhan lalar, sebelah barat berbatasan dengan selat alas. Warna tanah yaitu sebagian besar berwarna merah, kuning, hitam dan abu-abu dengan tekstur tanah yaitu lempung, pasir dan berdebu.

Pentingnya pangan sebagai kebutuhan paling mendasar bagi setiap manusia menjadikan pemenuhan kebutuhan pangan merupakan prioritas utama dalam pembangunan. Ketahanan pangan mencakup faktor ketersediaan, distribusi dan konsumsi. Ketersediaan berarti tercukupinya pasokan pangan untuk memenuhi kebutuhan penduduk. Faktor distribusi adalah mewujudkan sistem distribusi yang efektif dan efisien untuk menjamin masyarakat agar dapat memperoleh pangan dalam jumlah, kualitas dan dengan harga yang terjangkau. Sedangkan konsumsi berarti mengarahkan pola pemanfaatan pangan agar memenuhi kaidah mutu, keragaman, kandungan gizi dan kehalalannya (Prabowo, 2010).

Kebutuhan pangan bagi manusia seperti sayuran dan buah-buahan semakin meningkat dengan seiring perkembangan jumlah penduduk. Namun hal tersebut tidak dibarengi dengan pertumbuhan lahan pertanian yang justru semakin sempit (Roidah, 2014).

Upaya pemenuhan kebutuhan pangan mendapatkan banyak tantangan dan rintangan akibat perubahan kondisi lingkungan, seperti perubahan iklim, alih fungsi lahan, dan semakin banyaknya kasus serangan hama dan penyakit tanaman yang menyebabkan terjadinya penurunan hasil panen. Oleh karena itu perlu dikembangan strategi baru dalam mengoptimalkan pemanfaatan lahan untuk meningkatkan kecukupan, ketahanan, dan kemandirian pangan masyarakat (Kusumo, 2020).
e-ISSN : 2715-2537

p-ISSN : 2715-2545

Kementerian Pertanian menginisiasi optimalisasi pemanfaatan pekarangan melalui konsep Rumah Pangan Lestari (RPL). Rumah Pangan Lestari (RPL) adalah rumah penduduk yang mengusahakan pekarangan secara intensif untuk dimanfaatkan dengan berbagai sumberdaya lokal secara bijaksana yang menjamin kesinambungan penyediaan bahan pangan rumah tangga yang berkualitas dan beragam. Apabila RPL dikembangkan dalam skala luas, berbasis dusun (kampung), desa, atau wilayah lain yang memungkinkan, penerapan prinsip Rumah Pangan Lestari (RPL) disebut Kawasan Rumah Pangan Lestari (KRPL). Program Kawasan Rumah Pangan Lestari ini merupakan kegiatan yang mendorong warga untuk mengembangkan tanaman pangan maupun peternakan dan perikanan skala kecil dengan memanfaatkan lahan pekarangan rumah. Jadi, ini merupakan terobosan dalam menghadapi perubahan iklim melalui pemanfaatan pekarangan dalam mendukung ketersediaan serta diversifikasi pangan. Seberapapun lahan pekarangan yang ada, bisa untuk menghasilkan pangan dari rumah, karena untuk warga yang memiliki lahan terbatas bisa tetap menanam dengan teknik vertikultur (Oka, dkk., 2016).

Lahan yang sempit bukan menjadi kendala untuk membuat lingkungan menjadi hijau dan indah. Vertikultur dikenal juga dengan beberapa istilah seperti taman tegak, green wall, taman vertical dan lain-lain (Noverita, 2005). Budidaya taman vertical atau vertikultur sangat menguntungkan bagi penduduk kota besar yang memiliki lahan terbatas.

Vertikultur merupakan teknik budidaya tanaman secara vertikal sehingga penanaman dilakukan secara bertingkat. Teknik budidaya ini tidak memerlukan lahan yang luas, bahkan dapat dilakukan pada rumah yang tidak memiliki halaman sekalipun. Teknik vertikultur ini memungkinkan untuk berkebun dengan memanfaatkan tempat secara efisien. Budidaya tanaman vertikal atau vertikultur sanagat menguntungkan bagi penduduk kota besar yang memiliki lahan terbatas. Teknologi vertikultur bisa untuk berbagai jenis tanaman seperti bayam merah, seledri, sawi, tomat, pare, kacang panjang dan mentimun (Hidayati, dkk.,2018). Tanaman bayam biasanya tumbih di daerah tropis dan menjadi tanaman sayur yang penting bagi masyarakat di daerah rendah. Bayam merupakan tanaman yang berumur tahunan, cepat 
Hakim et al, Jurnal Pengabdian Masyarakat Sains Indonesia 2021, 3 (1): 226-234. DOI: https://doi.org/10.29303/jpmsi.v3i1.107

tumbuh serta mudah ditanam pada kebun ataupun ladang (Palada dan Chang, 2003).

Kelebihan vertikultur kualitas produk lebih baik dan lebih bersih, kuantitas produk lebih tinggi dan kontinuitas produksi dapat dijaga, menjadi lahan bisnis baik langsung maupun tidak langsung, dapat digunakan sebagai sumber tanaman obat keluarga, menambah dan memperbaiki gizi keluarga, selanjutnya efisiensi lahan, pupuk, air, benih, dan tenaga kerja, dan yang terakhir menghilangkan stress atau mengurangi beban pikiran. Sedangkan kelemahan dari vertikultur adalah rawan terhadap serangan jamur, investasi awal yang dibutuhkan cukup tinggi, apabila menggunakan atap plastic maka harus dilakukan penyiraman tiap hari, perlu tangga atau alat khusus yang dapat dinaiki untuk pemeliharan dan pemanenan di lantai atas (Rasapto, 2006).

Salah satu upaya mengoptimalkan pertumbuhan dan produktivitas tanaman adalah dengan pemberian pupuk kompos. Kompos merupakan pupuk organik yang berasal dari sisa tanaman dan kotoran hewan yang telah mengalami proses dekomposisi atau pelapukan. Proses pembuatan kompos (komposting) dapat dilakukan dengan cara aerobik maupun anaerobik. Proses pengomposan adalah proses menurunkan $\mathrm{C} / \mathrm{N}$ bahan organik hingga sama dengan $\mathrm{C} / \mathrm{N}$ tanah. Keunggulan dari pupuk kompos ini adalah ramah lingkungan, dapat menambah pendapatan peternak dan dapat meningkatkan kesuburan tanah dengan memperbaiki kerusakan fisik tanah akibat pemakaian pupuk anorganik (kimia) secara berlebihan (Subekti, 2015).

\section{Metode}

Kegiatan dilakukan selama 45 hari dimulai pada tanggal 11 Januari 2021 Sampai tanggal 25 Februari 2021 di kelurahan Telaga Bertong, Lingkungan Telaga Baru A, Kecamatan Taliwang, Kabupaten Sumbawa Barat.

Metode kegiatan selama Kerja Kuliah Nyata $(\mathrm{KKN})$ di Kelurahan Telaga Bertong Tepatnya di Desa Telaga Baru A diantaranya:

\section{a. Mempersiapkan alat dan bahan.}

Alat - alat yang digunakan pada kegiatan penanaman pangan lestari dan pembuatan pupuk adalah polybag, sekop, cangkul, karung, tray telur, terpal, paku, botol, palu, bambu,
e-ISSN : 2715-2537

p-ISSN : 2715-2545

gergaji, gerinda, mesin bor, mesin ketam, amplas, papan kayu, baja ringan, plastik atap, timbangan. Adapun bahan yang digunakan yaitu benih terong, benih cabai, benih kol, benih kangkung, benih sawi, benih seledri, benih salada, benih bayam, abu, sekam, kotoran ternak, kapur, EM4 pertanian, tanah, air, dan Nutrisi merek Enzim.

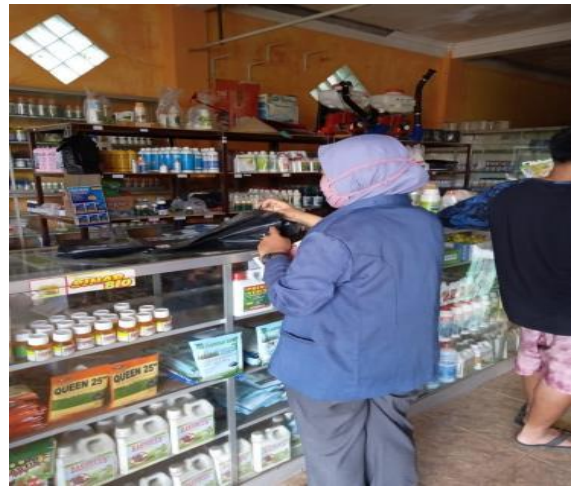

Gambar 1. Persiapan alat dan bahan

\section{b. Pengolahan Lahan}

Pengolahan lahan adalah proses membagi lahan untuk kebun bibit dan penanaman dengan metode vertikultur. Kegiatan yang dilakukan selama pengolahan lahan yaitu pembuatan bedengan seluas $1 \times 3$ meter, rak bertingkat $1 \times$ 6 meter, pengisian pasir dan terumbu karang ke dalam kebun bibit, dan pemasangan plastik pada atap kebun bibit dengan tujuan untuk melindungi bibit-bibit sayuran dari curah hujan yang berlebih.

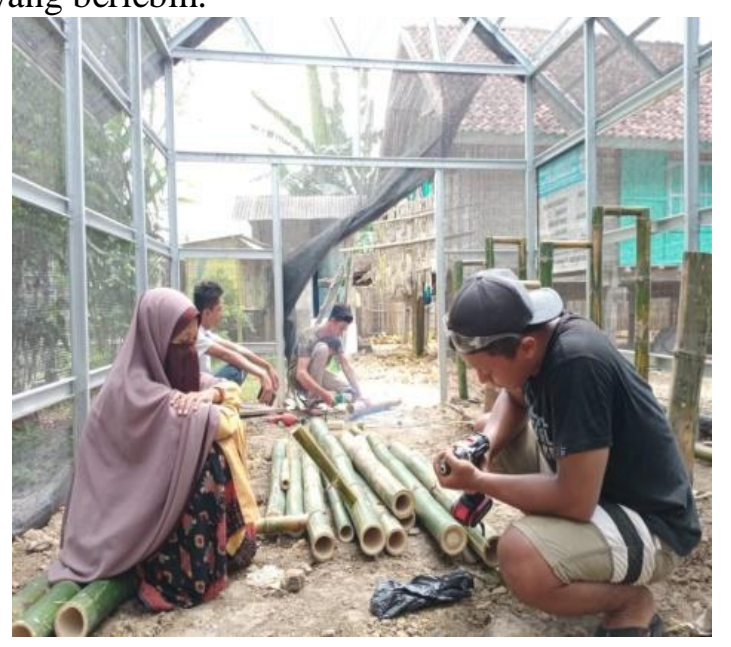

Gambar 2. Pembuatan Rak

\section{c. Penyemaian}

Penyemaian adalah kegiatan memproses benih menjadi bibit. Penyemaian ini diperlukan 
Hakim et al, Jurnal Pengabdian Masyarakat Sains Indonesia 2021, 3 (1): 226-234 DOI: https://doi.org/10.29303/jpmsi.v3i1.107

ketika benih terlalu kecil sehingga jika ditanam langsung akan rentan hanyut atau hilang terbawa air. Dalam proses penyemaian ada beberapa benih yang sudah disemai diantaranya yaitu benih sawi, benih kol, benih cabai, benih bayam, benih salada, benih seledri dan benih terong. Selama proses penyemaian media tanam yang digunakan adalah tanah yang dicampurkan dengan sekam padi atau serbuk gergaji yang dimana tujuannya agar tanah tidak terlalu menggumpal. Proses penyemaian benih di semai pada tray telur selama kurang lebih 14 hari,

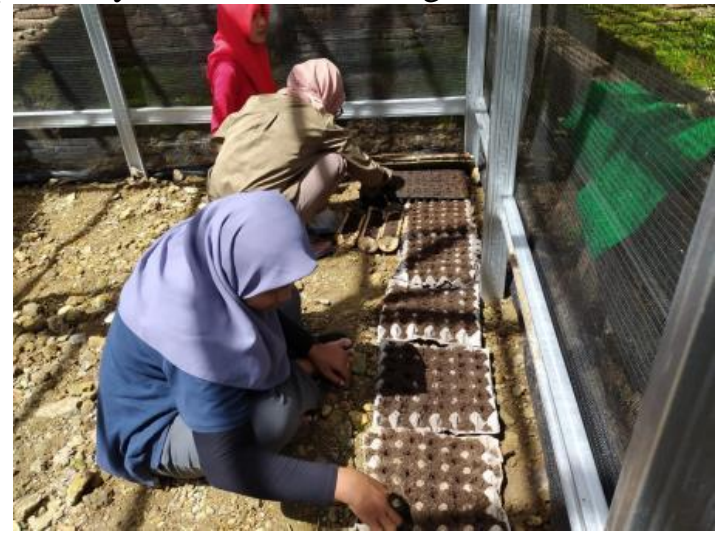

Gambar 3. Proses penyemaian

\section{d. Pemindahan Bibit}

Pemidahan bibit merupakan suatu tahapan memindahkan benih yang telah tumbuh menjadi bibit dari tray telur ke dalam polybag. Kemudian dipisahkan satu per satu agar mengurangi persaingan nutrisi antar tanaman.

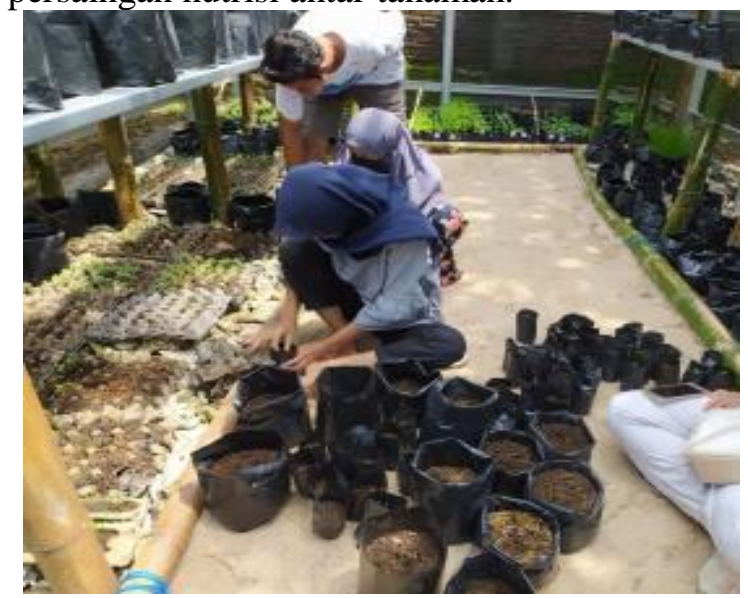

Gambar 4. Pemindahan Bibit

e. Pembuatan Pupuk Kompos

1) Persiapan Alat dan Bahan

Menyiapkan alat dan bahan yang akan digunakan untuk membuat pupuk kompos
e-ISSN : $2715-2537$

p-ISSN : 2715-2545

dari kotoran ternak. Adapun alat dan bahan yang digunakan dalam pembuatan pupuk yaitu kotoran ternak kerbau kering, abu, serbuk gergaji, kapur dan EM4.

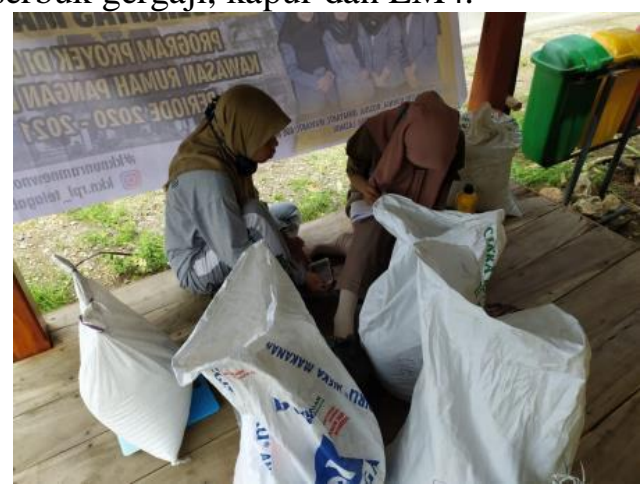

Gambar 5 . Persiapan bahan- bahan pembuatan pupuk

2) Pembuatan Pupuk

Proses pembuatan pupuk kompos ini yaitu dengan mencampurkan kotoran ternak dengan serbuk gergaji, abu dan kapur. Kemudian di campurkan EM4 yang sudah dilarutkan dalam air. Setelah itu pupuk yang sudah dibuat di fermentasikan kedalam terpal selama 3 minggu. Manfaat kompos organic diantaranya adalah memperbaiki struktur tanah berlempung sehingga menjadi ringan, memperbesar daya ikat tanah berpasir sehingga tanah tidak berderai, menambah daya ikat tanah terhadap air dan unsur hara tanah, memperbaiki drainase dan tata udara tanah, mengandung unsur hara yang lengkap walaupun jumlahmya sedikit (jumlah ini tergantung dari bahan pembuat pupuk organic), kemudian, membantu proses pelapukan bahan mineral, memberi ketersediaan bahan makanan bagi mikroba serta menurunkan aktifitas mikroba yang merugikan (Yovita, 2001).

Pengolahan kotoran sapi yang mempunyai kandungan $\mathrm{N}$, $\mathrm{P}$, dan $\mathrm{K}$ yang tinggi sebagai pupuk kompos dapat mensuplai unsur hara yang dibutuhkan tanah dan memperbaiki struktur tanah menjadi lebih baik (Setiawan, 2002). 
Hakim et al, Jurnal Pengabdian Masyarakat Sains Indonesia 2021, 3 (1): 226-234 DOI: https://doi.org/10.29303/jpmsi.v3i1.107

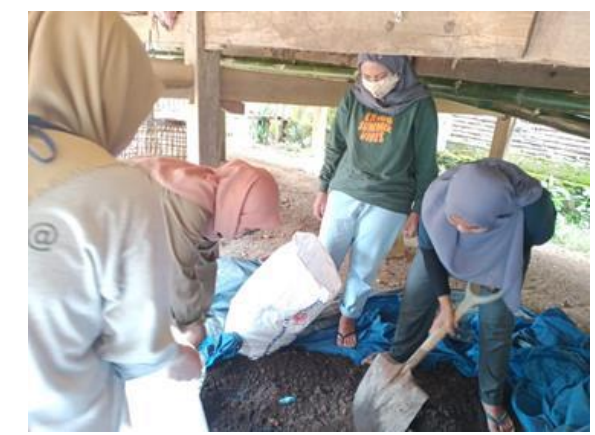

Gambar 6. Proses pencampuran bahan pembuatan pupuk

3) Fermentasi

Fermentasi merupakan proses penguraian bahan organic yang dibantu oleh mikroorganisme. Fermentasi dapat dilakukan dengan dua cara yaitu spontan dan tidak spontan. Fermentasi spontan adalah yang tidak ditambahkan mikroorganisme dalam bentuk starter, sedangkan fermentasi tidak spontan adalah yang ditamhakan starter dalam proses pembuatannya (Suprihatin, 2010). Dimana Kompos yang semakin lama difermentasi cenderung menghasilkan warna yang lebih gelap. Fermentasi kotoran ternak kerbau ini dilakukan selama 3 minggu dimana setiap minggu pupuk organiknya dibalik.

4) Hasil

Setelah kotoran ternak menjadi pupuk kompos, dilakukan proses pengemasan. Pupuk kompos dikemas kedalam karung, setelah itu baru disebarkan ke tanaman sayuran organic untuk dijadikan pupuk organik.

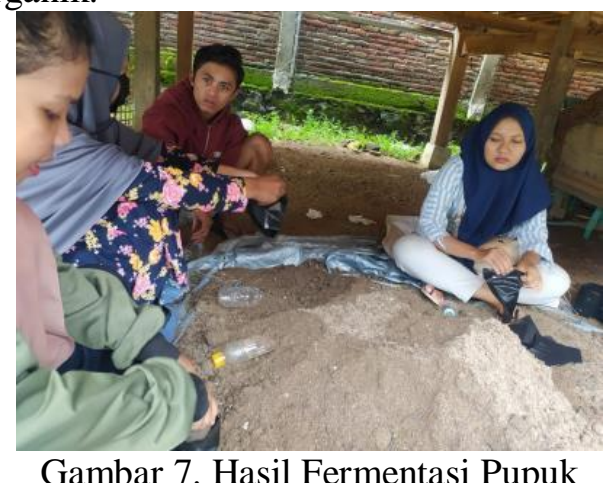

\section{f. Monitoring dan Evaluasi}

Monitoring adalah tahapan untuk mengetahui perkembangan bibit dengan
e-ISSN : $2715-2537$

p-ISSN : 2715-2545

melakukan pengecekan terhadap tanaman pada pagi hari dan dilakukan penyiraman pagi dan sore hari. Kemudian evaluasi adalah tahapan untuk mengevaluasi sejauh mana keberhasilan dari penanaman.

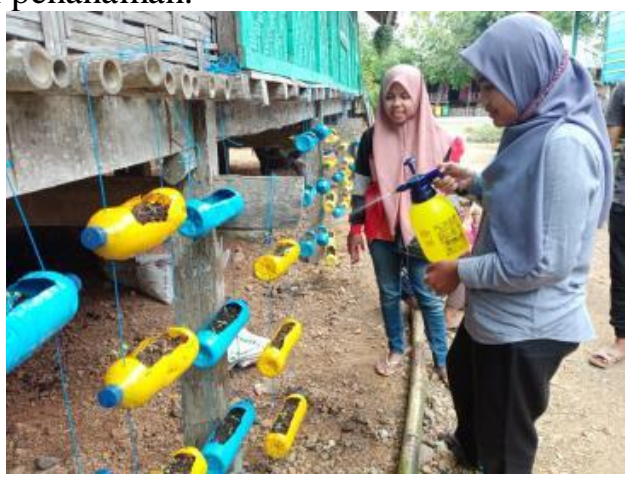

Gambar 8. Penyiraman Bibit

\section{Hasil dan Pembahasan}

Program pemanfaatan lahan dalam meningkatkan ketahanan pangan nasional di Kelurahan Telaga Bertong, Lingkungan Telaga Baru A dilakukan secara terstruktur dan melibatkan perangkat desa untuk ikut andil dalam program ini. Program ini diharapkan mampu menjadi solusi bagi masyarakat dalam memanfaatkan pekarangan rumahnya.

\section{A. Pelaksanaan Program Pemberdayaan} Masyarakat.

Kegiatan program pemberdayaan masyarakat melalui kawasan rumah pangan lestari dimulai dengan persiapan program kerja yang meliputi survey lokasi dan keadaan sosial masyarakat Lingkungan Telaga Baru A Kelurahan Telaga Bertong yang dilakukan untuk mengetahui potensi dan masalah yang ada di Lingkungan Telaga Baru A Kelurahan Telaga Bertong.

\section{B. Sosialisasi}

Lingkungan Telaga Baru A, Kelurahan Telaga Bertong yang dijadikan kawasan rumah pangan lestari ini memiliki hasil tani utama dan lebih fokus pada tanaman padi dan palawija, sehingga ketersediaan sayuran yang dihasilkan oleh petani di daerah tersebut sangat minim. Hal ini dikarenakan masih kurangnya pemahaman masyarakat mengenai bagaimana cara memanfaatkan lahan pekarangan rumah sebagai tempat untuk bercocok tanam dengan berbagai metode seperti vertikultur, hidroponik, aeroponik dan aquaponik. Menurut Ihrom 
Hakim et al, Jurnal Pengabdian Masyarakat Sains Indonesia 2021, 3 (1): 226-234. DOI: https://doi.org/10.29303/jpmsi.v3i1.107

(2004) Sosialisasi adalah proses belajar yang dialami seseorang untuk memperoleh pengetahuan keterampilan, nilai-nilai dan norma-norma agar ia dapat berpartisipasi sen=bagai anggota dalam kelompok masyarakat. Sosialisasi dilakukan dengan tujuan untuk mengenalkan program kerja kepada masyarakat dari penyamaian bibit, pengambilan tanah, pembuatan pupuk organik serta pemindahan bibit ke dalam polybag dengan menggunakan metode vertikultur. Dengan adanya sosialisasi ini diharapkan masyarakat kedepannya bisa memanfaatkan pekarangan rumahnya untuk dijadikan tempat untuk menanam sayuran organic sehingga dapat meningkatkan ketahanan pangan.

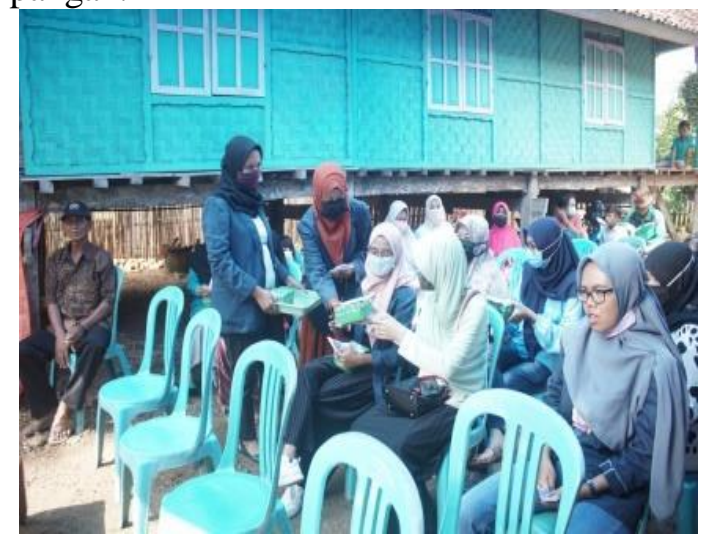

Gambar 9. Kegiatan Sosialisasi

\section{Pembagian Bibit}

Bibit merupakan salah satu penentu keberhasilan budidaya tanaman. Budidaya tanaman sebenarnya telah dimulai sejak memilih bibit tanaman yang baik, karena bibit merupakan obyek utama yang akan dikembangkan dalam proses budidaya selanjutnya (Setiawan, 1999). Tujuan dari pembagian bibit ini adalah untuk meningkatkan ketahanan pangan masyarakat sekitar Lingkungan Telaga Baru A, terlebih lagi di situasi pandemic COVID-19 seperti saat ini. Bibit yang dibagikan kepada masyarakat sekitar berupa bibit cabai, kol, sawi, bayam, terong ungu, terong lalap, kangkung, seledri dan selada. Dengan terlaksananya program pembagian bibit sayuran ini, mahasiswa KKN Tematik Universitas Mataram berharap bibit yang diberikan bisa tumbuh dengan baik dan bisa bermanfaat bagi masyarakat Telaga Baru A untuk memenuhi kebutuhan sayuran keluarga dan memperkuat ketahanan pangan di lingkungan tersebut.

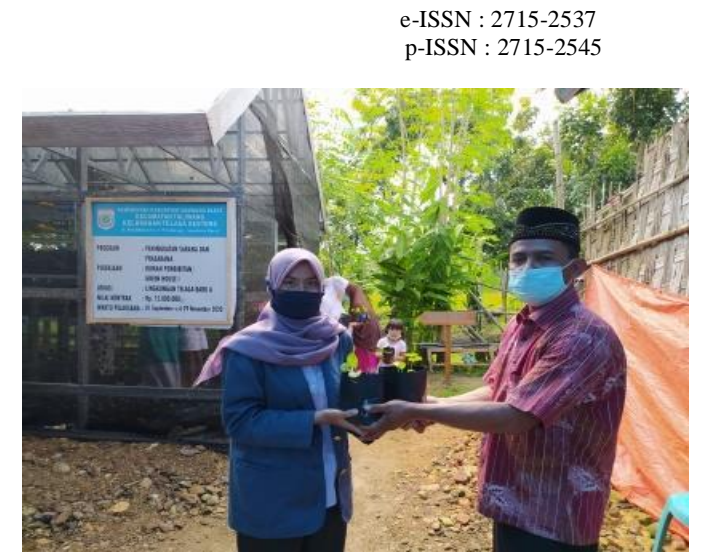

Gambar 10. Penyerahan Bibit Kepada Kepala Lingkungan

\section{Gotong Royong}

Gotong royong merupakan kegiatan sosial kemasyarakatan yang berorientasi pada tindakan untuk saling meringankan beban pekerjaan. Perilaku masyarakat dalam kegiatan gotong royong menunjukkan bentuk solidaritas dalam kelompok masyarakat tersebut. Gotong royong merupakan ciri budaya bangsa Indonesia yang berlaku secara turun-temurun sehingga membentuk perilaku sosial yang nyata dalam tata nilai kehidupan sosial. Nilai tersebut menjadikan kegiatan gotong royong selalu terbina dalam kehidupan komunitas sebagai suatu warisan budaya yang patut untuk dilestarikan. Aktifitas gotong royong dilakukan oleh warga komunitas baik yang tinggal di pedesaan maupun di perkotaan. Meski demikian masing-masing mempunyai nilai yang berbeda. Aktivitas gotong royong di perkotaan sudah banyak di pengaruhi oleh materi dan sistem upah. Sedangkan di perdesaan gotong royong sebagai suatu solidaritas antar sesama masyarakat dalam satu kesatuan wilayah atau kekerabatan.

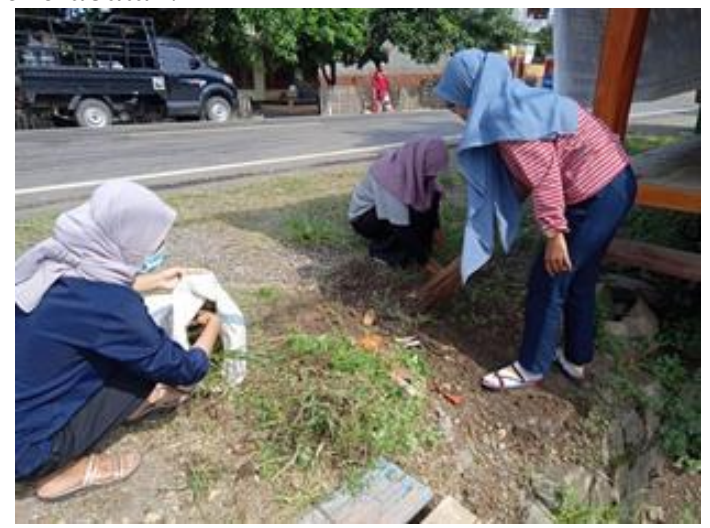

Gambar 11. Kegiatan Gotong Royong 
Hakim et al, Jurnal Pengabdian Masyarakat Sains Indonesia 2021, 3 (1): 226-234. DOI: https://doi.org/10.29303/jpmsi.v3i1.107

\section{E. Clean up}

Permasalahan yang sering terjadi di daerah pantai dan pesisir adalah pencemaran lingkungan yang akan berdampak pada kerusakan organisme yang hidup di daerah tersebut. Sampah di lingkungan pantai dapat meracuni fitoplankton yang pada akhirnya dapat menurunkan kesuburan suatu perairan (Hutabarat dalam Awaluddin et al., 2011). Beberapa sampah yang banyak terdapat di Pantai poto batu dan pantai pasir putih adalah sampah dalam bentuk plastik.

Salah satu dalam mendukung kebersihan pantai adalah adanya kegiatan aktif oleh masyarakat. Masyarakat dalam hal ini adalah masyarakat sekitar pantai maupun pengguna pantai baik dari turis lokal maupun dari luar.

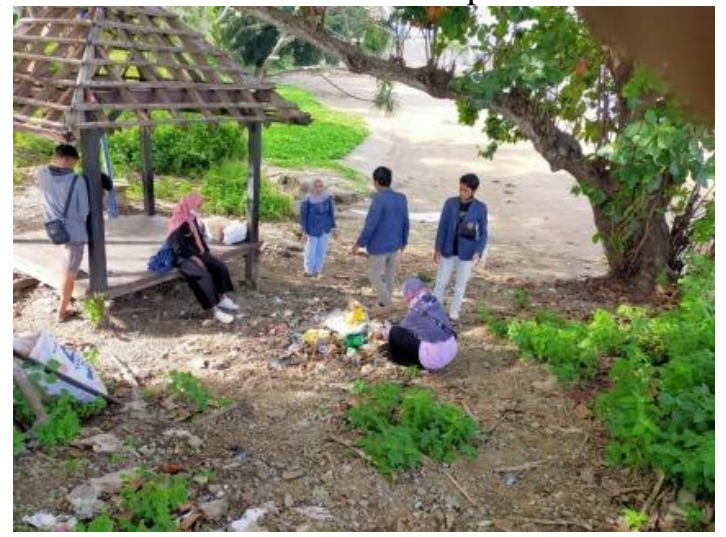

Gambar 12. Clean Up Pantai

\section{F. Mengajar}

Menurut Djamarah dan Zain 2010 mengajar pada hakikatnya adalah suatu proses, yaitu proses mengatur, mengorganisasi lingkungan yang ada disekitaranak didik, sehingga dapat menumbuhkan dan mendorong anak didik melakukan proses belajar. Kegiatan belajar mengajar dilakukan guna untuk melatih anak-anak dalam mengetahui karya seni dengan metode menggambar dan membuat suatu karya seni tangan berupa jam es krim dari kertas origami.

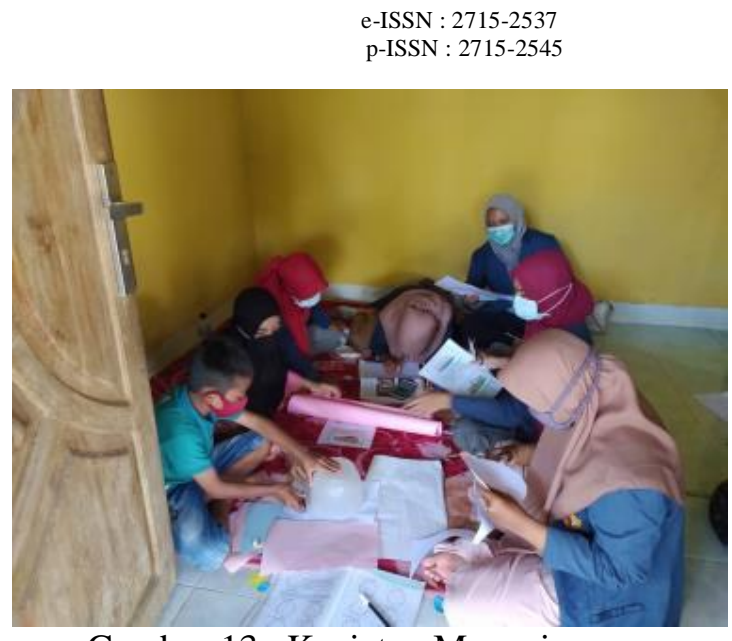

Gambar 13 . Kegiatan Mengajar

\section{G. Kunjungan}

Kunjungan dilakukan guna untuk berbagi pengetahuan dengan berbagai metode Hidroponik dalam penanaman bibit pangan lestari yang dilaksanakan oleh kelompok RPL di Desa Moteng A. Hidroponik adalah suatu metode bercocok tanam tanpa menggunakan media tanah, melainkan dengan menggunakan larutan mineral bernutrisi atau bahan lainnya yang mengandung unsur hara seperti sabut kelapa, serat mineral, pasir, pecahan batu bata, serbuk kayu, dan lain-lain sebagai pengganti media (Mulasari, 2018).

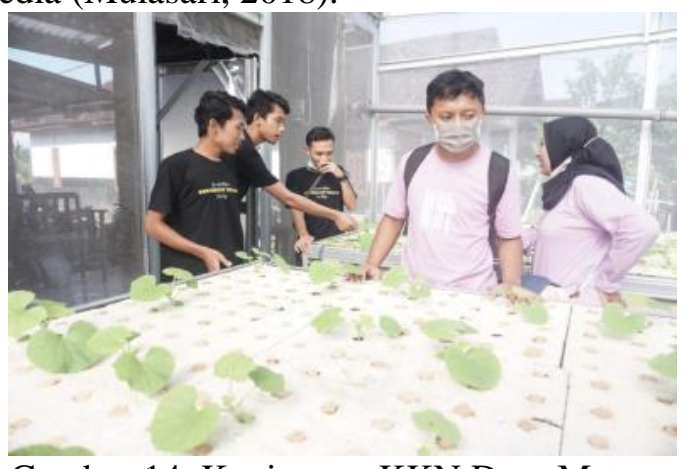

Gambar 14. Kunjungan KKN Desa Moteng

\section{H. Penanaman Pohon}

Kegiatan penanaman pohon merupakan kegiatan inti dari budidaya hutan. Hutan yang mencakup areal yang luas, memerlukan biaya yang besar sehingga diperlukan keterampilan yang cukup. Kegiatan penanaman meliputi pemilihan jenis, persiapan lapangan, pemasangan ajir, pembuatan lubang tanam, pengangkutan bibit, penanaman, penyulaman serta pemeriksaan pekerjaan dan evaluasi penanaman (Budi, 2006). Penanaman pohon memiliki manfaat bagi kelangsungan makhluk 
Hakim et al, Jurnal Pengabdian Masyarakat Sains Indonesia 2021, 3 (1): 226-234. DOI: https://doi.org/10.29303/jpmsi.v3i1.107

hidup yang ada di alam. Pesatnya pembangunan menyebabkan banyak pohon yang ditebang. Dengan denikian panas bumi meningkat serta jumlah pasokan air dalam tanah semakin berkurang. Oleh karena itu, dengan menanam pohon di sekitar air terjun "Kalela Jereweh" dapat menyerap polutan tertentu dan menyaring debu yang banyak kita temukan di udara wisata air terjun "Kalela Jereweh". Dengan demikian kita harus bersinergi, berbagi peran untuk menjaga bumi kita tetap lestari. Menanam pohon berarti kita telah mengimplementasikan cara menata lingkungan yang baik, dan menyelamatkan sumber air, serta mempertahankan udara bersih.

Salah satu langkah yang dilakukan untuk meningkatkan rasa kepedulian terhadap lingkungan adalah dengan menjadi sukarelawan untuk penanaman bibit pohon di air terjun "Kalela Jereweh". Tanaman yang terdapat di air terjun "Kalela Jereweh" akan memberikan kontribusi yang cukup penting untuk sirkulasi udara yang segar dan bersih bagi masyarakat yang ada disekitar kawasan dan manfaat yang baik tentunya bagi masyarakat jereweh.

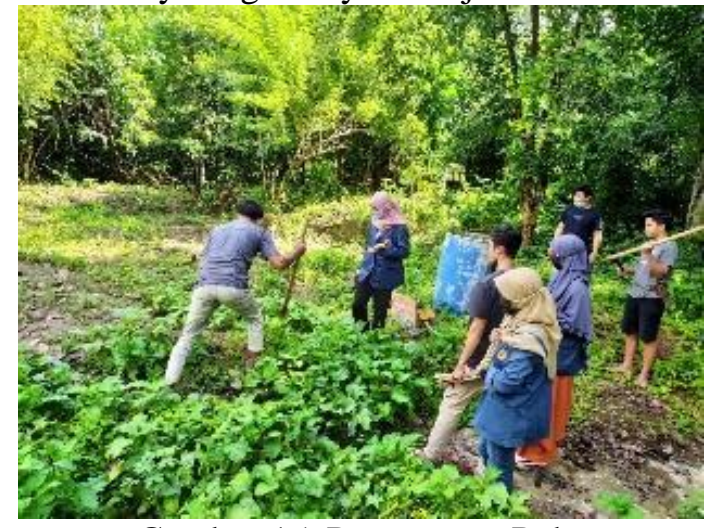

Gambar 15. Penanaman Pohon

\section{Membersihkan Masjid}

Pada kegiatan pembersihan masjid dilakukan dua kali pada hari Jumat yang berbeda. Kegiatan pembersihan meliputi menyapu dan mengepel lantai, membersihkan jarring laba-laba di dinding dan di plafon, membersihkan halaman masjid dari rumput liar, serta penyemprotan desinfektan di bagian lantai dan pekarangan masjid. Pembersihan ini dilakukan pada pagi hari sehingga pada waktu pelaksanaan sholat Jumat masjid sudah dalam keadaan bersih dan steril.

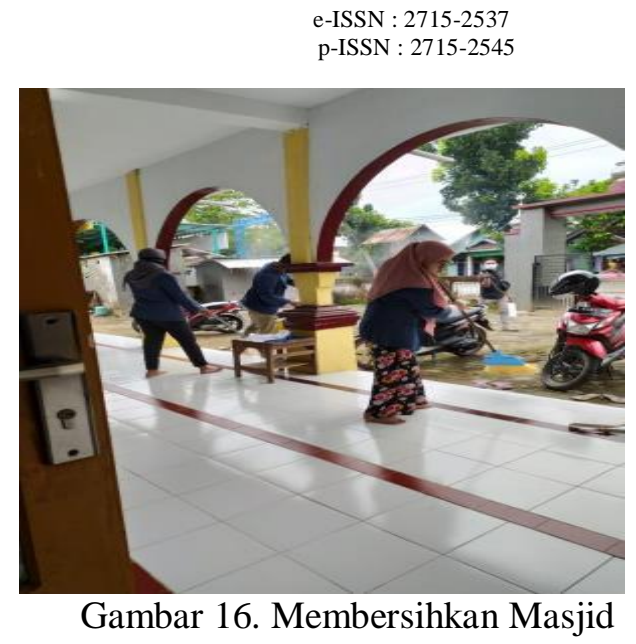

\section{J. Mengikuti Kegiatan Posyandu}

Posyandu merupakan kegiatan yang dilakukan setiap bulan oleh petugas dari puskesmas dan polindes dibantu oleh ibu-ibu kader. Kegiatan posyandu meliputi penimbangan berat badan, mengukur tinggi badan, pemberian vitamin dan biscuit susu kepada bayi dan balita, serta melakukan pengukuran tensi untuk ibu hamil. Kegiatan ini bertujuan untuk mengevaluasi pertumbuhan dan kesehatan bayi, balita dan ibu hamil.

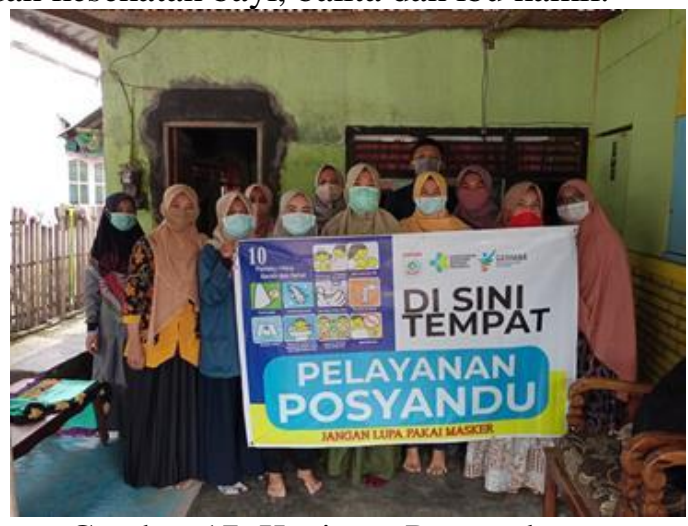

Gambar 17. Kegiatan Posyandu

\section{Kesimpulan}

Kegiatan KKN tematik regular Universitas Mataram dilakukan di lingkungan Telaga Baru A, kelurahan Telaga Bertong. Program utama yang dilaksanakan adalah pembuatan kebun bibit dengan metode vertikultur untuk kawasan rumah pangan lestari dan sosialisasi tentang KRPL dilanjutkan dengan pembagian bibit sayuran kepada masyarakat sekitar di akhir masa KKN. Selain itu ada juga beberapa program tambahan yang dilaksanakan yaitu gotong royong, clean up pantai, kunjungan, mendampingi kegitan belajar dari 
Hakim et al, Jurnal Pengabdian Masyarakat Sains Indonesia 2021, 3 (1): 226-234 DOI: https://doi.org/10.29303/jpmsi.v3i1.107

rumah untuk adik-adik SD, membantu kegiatan Posyandu, dan pembersihan masjid.

\section{Saran}

Penulis menuarankan agar dilakukan kegiatan lanjutan mengenai penelitian ini sehingga masyarakat lebih memahami mengenai pemanfaatan lahan dalam meningkatkan ketahanan pangan nasional khususnua di Kelurahan Telaga Bertong, Desa Telaga Baru A.

\section{Ucapan Terima Kasih}

Penulis mengucapkan terima kasih kepada Universitas Mataram khususnya kepada LPPM yang telah menfasilitasi kegiatan penelitian ini melalui program KKN. Kemudian penulis juga mengucakpakan terima kasih kepada masyarakat Telaga Baru A yang telah membantu mensukseskan penelitian ini. Serta semua pihak yang terlibat dalam penelitian ini atas segala kerjasamanya selama pelaksanaan kegiatan ini.

\section{Daftar Pustaka}

Awaluddin, M. Y. (2011). Introduksi Konsep Bersih Pantai (Coastal Cleanup) di Pantai Sidangkerta, Kecamatan Cipatuja, Kabupaten Tasikmalaya. Jurna Harpodon Borneo. 4(2): 1-6).

Budi, S.W. 2006. Modul Pelatihan Penanaman Pohon. Jawa Barat:IPB.

Djamarah, S.B., dan A. Zain. 2010. Strategi Belajar Mengajar. Jakarta: Rinekacipta.

Hidayati, N., Rosawanti, P., Arfianto, F., \& Hanafi, N. (2018). Pemanfaatan Lahan Sempit Untuk Budidaya Sayuran dengan Sistem Vertikultur. Pengabdianmu, 3(1), 40-46.

Ihrom. 2004. Bunga Rampai Sosiologi Keluarga. Jakarta:Yayasan Obor Indonesia.

Kelurahan Telaga Bertong. 2020. Profil Kelurahan Telaga Bertong. Kelurahan Telaga Bertong.

Kusumo, RAB, Sukayat, D, dkk. 2020. Budidaya Sayuran Dengan Teknik Vertikultur Untuk Meningkatkan Ketahanan Pangan Rumah Tangga Di Perkotaan. Dharmakarya: Jurnal Aplikasi Ipteks untuk Masyarakat Vol. 9. No. 2. ISSN 1410 - 5675.
e-ISSN : 2715-2537

p-ISSN : 2715-2545

Mulasari, S. A. (2018). Penerapan Teknologi Tepat Guna (Penanam Hidroponik Menggunakan Media Tanam) Bagi Masyarakat Sosrowijayan Yogyakarta. Jurnal Pemberdayaan: Publikasi Hasil Pengabdian Kepada Masyarakat. 2(3): 425-430.

Noverita, S. 2005. Pengaruh Konsentrasi Pupuk Pelengkap Cair Nikaplus dan Jarak Tanam Terhadap Pertumbuhan dan Produksi tanaman Baby Kaylan (Brassica oleraceae L) Secara Vertikultur. Jurnal Penelitian Bidang Ilmu Pertanian, 3 (1):21-29.

Oka, I. A., Darmawan, D. P., \& Astiti, N. W. (2016). Keberhasilan Kawasan Rumah Pangan Lestari (KRPL) pada Kelompok Wanita Tani di Kabupaten Glanyar. Jurnal Manajemen Agribisnis, 4(2), 133-146.

Palada, M. C., And Chand. 2003. Suggested Cultural Pratice for Moringa. Asian Vegetables Research and Development Center. 1-2.

Prabowo, R. 2010. Kebijakan pemerintah dalam mewujudkan ketahanan pangan di Indonesia Mediagro, 6(2), 62-73.

Rasapto, P. W. (2006). Budidaya Sayuran dengan Vertikultur. Jawa Tengah: Balai Pertanian Teknologi Jawa Tengah.

Roidah, IS. 2014. Pemanfaatan Lahan Dengan Menggunakan Sistem Hidroponik. Jurnal Universitas Tulungagung BONOROWO Vol. 1.No.2.

Setiawan A.I. 2002. Manfaat Kotoran Ternak. Jakarta: Penebar Swadaya.

Setiawan, A.I. 1999. Kiat Memilih Tanaman Buah. Jakarta: Penebar Swadaya.

Subekti, K. (2015). Pembuatan Kompos dari Kotoran Sapi (Komposting). Yogyakarta: Universitas Gadjah Mada.

Suprihati. 2010. Teknologi Fermentasi. Surabya:UNESA Press.

Wikipedia. 2016. Telaga Bertong, Taliwang, Sumbawa Barat. [Diakses 4 Januari 2020]. HYPERLINK

"https://Id.Wikipedia.Org/Wiki/Telaga_Ber tong,Taliwang_Sumbawa_Barat" https://Id.Wikipedia.Org/Wiki/Telaga_Bert ong,Taliwang_Sumbawa_Barat

Yovita. 2001. Membuat Kompos Secara Kilat. Penebar Swadaya. Jakarta. 